\title{
LeR Info: uma proposta de material didático digital para o ensino de leitura e produção do gênero multimodal infográfico no Google Classroom
}

Marileia da Silva Marchezan" Susana Cristina dos Reis"

\section{Resumo}

Em Linguística Aplicada, pesquisas reportam análise de gêneros discursivos e multimodais e trazem sugestões de sequências didáticas para uso em aulas, porém, raramente se encontra a descrição de materiais digitais para aulas de língua portuguesa na modalidade híbrida e que evidenciem a linguagem como prática social. Com base nessas premissas, desenvolvemos material didático digital para promover o ensino de leitura e de escrita,por meio do Google Classroom, na perspectiva da pedagogia crítica de gêneros.Para avaliar o material, realizamos uma açãoem uma escola pública, em cuja experiência os participantes consumiram, produziram eêneroáfico.Os resultados foram positivos à aprendizagem ínguapor meio da proposta aplicada, pois gerou engajamento, motivação e retenção de conhecimento sobre o gênero, a partir do envolvimento dos alunos em diferentes práticas sociais pelo uso.

Palavras-chave: Linguagem como prática social. Material didático digital. Gênero multimodal infográfico. Google Classroom. Leitura e produção textual.

\section{Introdução}

O Indicador de Alfabetismo Funcional (Inaf) divulgou, em 2017, que há uma estimativa de que $27 \%$ da população do país seja analfabeta funcional. Embora esse dado seja amplo, isso evidencia também o que observamos diariamente nas práticas escolares, principalmente quanto à falta de interesse e de motivação dos alunos tanto pelo estudo da gramática quanto pela leitura e produção de textos.

\footnotetext{
* Docente da rede pública estadual do RS. Mestra em Tecnologias Educacionais em Rede (UFSM). E-mail: marileiamarchezan@gmail.com

* Professora Associada 2, Docente do Departamento de Letras Estrangeiras Modernas e do Programa de Pós-graduação Mestrado Profissional de Tecnologias Educacionais em Rede. Líder do GRPESQ/CNPq - Núcleo de Pesquisa, Ensino e Aprendizagem de Línguas a Distância (NUPEAD)/UFSM. E-mail: susana.reis@ ufsm.br
}

Data de submissão: set. 2020 - Data de aceite: nov. 2020 http://dx.doi.org/10.5335/rdes.v16i3.11431 
Ao identificarmos essas dificuldades na Educação Básica, percebemos que o contexto tradicional de ensino, nos moldes que ainda é proposto, não cativa mais os estudantes, haja vista que as tecnologias são mais atrativas e permitem aos alunos estudarem sozinhos, navegando e explorando conteúdos na $w e b$ que são coloridos, multimodais, interativos, engajadores, hipertextuais e dinâmicos (REIS, 2017). Como pesquisadoras na área da Linguística Aplicada, tal constatação levou-nos a propor neste estudo o uso da linguagem como prática social, na perspectiva da pedagogia de gêneros e de multiletramentos, buscando implementar tal concepção na produção de material didático digital (doravante MDD).

$\mathrm{Na}$ tentativa de identificarmos diretrizes para promover a aprendizagem da língua materna, em contexto escolar, procuramos na literatura recente pesquisas que mostrassem alternativas de pressupostos teóricos e de MDD para aulas de Língua Portuguesa (LP) que favorecessem a prática de leitura e de escrita de gêneros multimodais (RIBEIRO, 2016; ROJO, 2012; ROJO; BARBOSA, 2015). Porém, ao mapearmos estudos publicados entre o período de maio de 2017 a junho de $2018^{1}$, notamos que pouco ainda se discutia nas publicações acadêmicas sobre materiais digitais que explorassem gêneros multimodais pelo uso de tecnologias digitais (CECCHIN, 2015; COSCARELLI, 2016).
No Brasil, diversos estudos reportam análise de gêneros discursivos e multimodais e trazem sugestões de sequências didáticas (MOTTA-ROTH, 2002, 2006; SOJO, 2000; FUZER, 2012, 2014; SOUZA, 2012; ROJO, 2012; ROJO; BARBOSA, 2015; DIONÍSIO, 2008; CATTO; HENDGES, 2010; JESUS; CARBONIERI, 2016; RIBEIRO, 2016), porém, raramente se encontra a descrição de materiais digitais para uso em aula de LP (COSCARELLI, 2016). Há, ainda, poucas publicações com descrição de material digital em formato de curso híbrido (CECCHIN, 2015).

A partir desse levantamento, este artigo se propõe a preencher essa lacuna ao apresentar uma proposta de MDD que contribua para os processos de ensino e de aprendizagem, por meio de análise, produção e disseminação do gênero multimodal infográfico na modalidade híbrida (MARCHEZAN, 2018) na perspectiva de ensino da linguagem como prática social. Acreditamos que é por meio de propostas didáticas teoricamente planejadas e bem estruturadas (REIS; GOMES, 2014; REIS, 2017) que podemos gerar em nossos alunos o mesmo deslumbramento e engajamento, que outras práticas sociais encontradas na rede os possibilitam, a fim de potencializar o interesse deles pela aprendizagem da linguagem de modo significativo (HYLAND, 2007). 
Tendo em vista que nossos alunos são cada vez mais atraídos pelas tecnologias, e que o uso delas, em aulas de LP, exige planejamento para adequá-las ao contexto escolar (REIS, 2017), no estudo de Marchezan (2018, p. 29), investigamos quais atividades ou tarefas com gêneros multimodais podem ser elaboradas ou podem contribuir para a aprendizagem da LP e a prática de multiletramentos. Para isso, planejamos, desenhamos e aplicamos uma proposta de MDD, o qual nomeamos como LeR Info - Ler e Redigir Infográficos Online, buscando implementar no design do material a concepção de linguagem como prática social e os pressupostos já supracitados (ROSE; MARTIN, 2012; COPE; KALANTZIS, 2008, 2015; ROJO, 2012; ROJO; BARBOSA, 2015).

Para reportar esse estudo, este artigo está organizado em seções: primeiramente, retomamos as pesquisas que discutem sobre materiais didáticos e o que entendemos por gêneros multimodais, bem como discutimos brevemente sobre a concepção de linguagem, de ensino e de aprendizagem com base em gêneros que fundamentam este estudo (ROSE; MARTIN, 2012; COPE; KALANTZIS, 2015). Após, descrevemos o contexto de pesquisa e as ações metodológicas. $\mathrm{Na}$ seção de análise de dados, descrevemos exemplos de atividades encontradas no curso híbrido e avaliamos a sua aplicação, por meio dos dados coletados por meio da pesquisa aplicada. Para concluir, discutimos os resultados obtidos pela experiência que descrevem os processos de consumo, produção e disseminação do gênero multimodal infográfico com o uso das tecnologias de informação e comunicação (TIC) em aulas de LP.

A avaliação da presente pesquisa apresenta resultados positivos quanto ao estudo e à compreensão do gênero multimodal infográfico por meio de tecnologias, já que a experiência favoreceu o engajamento, a motivação e a retenção do conhecimento sobre o gênero em estudo, corroborando desse modo para a prática de multiletramentos e o uso da linguagem em práticas sociais emergentes.

\section{Material didático digital na perspectiva de gêneros e multiletramentos}

Para elaborarmos uma proposta de MDD que explorasse gêneros multimodais e promovesse a prática de multiletramentos (COPE; KALANTZIS, 2008, 2015) nas práticas escolares, foi necessário entender como tais pressupostos podem ser aplicados no design do material a ser implementado.

Em vista disso, a partir de leituras prévias, concebemos que gêneros multimodais são textos que reúnem várias linguagens, visual, espacial, táctil, gestual, sonora, oral, escrita (WALSH, 2010; 
CATTO; HENDGES, 2010); e, mais que isso, segundo afirmam Cope e Kalantzis (2008, p. 197), esses gêneros exploram "múltiplos modos (linguístico, auditivo, espacial, gestual e visual)", pois se constituem de diferentes semioses (imagens, cores, texturas, formas, som, etc.), os quais utilizam "sistemas de signos ou sistemas semióticos" (CATTO; HENDGES, 2010, p. 3) para disseminarem-se.

Nesse sentido, como salienta Ribeiro (2013, p. 22), "é necessário pensar a leitura desses textos, mas não como uma ação aleatória e ingênua, mas como uma atuação informada pelos conhecimentos de como eles são planejados". Para isso, faz-se necessário estudá-los, desde a sua constituição retórica, função e usos, para posteriormente investigar estratégias de como trabalhar tais textos em uma perspectiva de multiletramentos no contexto de sala de aula.

Ao abordarmos o ensino da linguagem na perspectiva de gêneros, nos reportamos a Motta-Roth (2002, p. 78), quando a autora afirma que gênero "[...] pressupõe uma interconexão entre fatores textuais (da linguagem) e fatores contextuais (das relações sociais envolvidas)". Sendo assim, é necessário estudar os gêneros levando-se em conta o seu contexto sociocultural, seu meio de circulação, já que os gêneros discursivos estão presentes no nosso cotidiano, ou seja, "todas as nossas falas, sejam cotidianas ou formais, estão articuladas em um gênero de discurso" (ROJO; BARBOSA, 2015, p. 16).

Com isso, concebemos gêneros como atividades sociais com as quais nos envolvemos ao lermos, ouvirmos, falarmos e escrevermos, ou seja, são instâncias de uso da língua que são constituídas na e pela linguagem (MOTTA-ROTH, 2006; REIS, 2010, p. 16-17). Diante disso, inferimos que é importante o estudo de gêneros discursivos e multimodais em contexto escolar (MARCHEZAN, 2018, p. 21; CECCHIN, 2015; BITENCOURT, 2019), com vistas a promover no aluno a consciência de entender a linguagem como prática social (MOTTA-ROTH, 2002).

Dessa forma, acreditamos que se potencializa a dinamicidade da língua, e novos gêneros podem ser explorados como, por exemplo, os do contexto digital a fim de promover multiletramentos que, segundo Rojo (2012, p. 23), “a) são interativos (colaborativos); b) fraturam e transgridem as relações de poder estabelecidas; e c) são híbridos, fronteiriços, mestiços (de linguagens, modos, mídias e culturas)". Portanto, ao acessar novos gêneros, o aluno sente necessidade de explorar novos letramentos tais como o "digital (uso das tecnologias digitais), o visual (uso das imagens), o sonoro (uso de sons, de áudio), o informacional (busca crítica da informação)" (ROJO, 2012, p. 37), entre outros.

Sendo assim, para que a escola seja inclusiva e promova o consumo e a pro- 
dução de maior variedade de gêneros discursivos e multimodais, com vistas a desenvolver multiletramentos nos alunos, é preciso oportunizar que esses atores sociais tenham contato com diversos gêneros tais como: gráficos, infográficos, charges, histórias em quadrinhos, mapas, etc. (ROSE; MARTIN, 2012; RIBEIRO, 2016; ROJO; BARBOSA, 2015; ROJO; MOURA, 2012; COSCARELLI, 2016).

Para implementarmos essas novas práticas, inclusive, atualmente previstas na Base Nacional Comum Curricular (BNCC) (BRASIL, 2018), selecionamos o gênero infográfico para ser estudado em sala de aula e seguimos o ciclo de aprendizagem de leitura e escrita de gêneros proposto por Rose e Martin (2012, p. 64-66) para orientar o processo de consumo, produção e distribuição de gêneros multimodais.

Nessa perspectiva, para além da cultura do impresso (ou da palavra escrita), que deve continuar tendo centralidade na educação escolar, é preciso considerar a cultura digital, os multiletramentos e os novos letramentos ${ }^{60}$, entre outras denominações que procuram designar novas práticas sociais de linguagem. No entanto, a necessária assunção dos multiletramentos não deve apagar o compromisso das escolas com os letramentos locais e com os valorizados. É preciso garantir que as juventudes se reconheçam em suas pertenças culturais, com a valorização das práticas locais, e que seja garantido o direito de acesso às práticas dos letramentos valorizados.
(...) Não são somente novos gêneros que surgem ou se transformam (como post, tweet, meme, mashup, playlist comentada, reportagem multimidiática, relato multimidiático, vlog, videominuto, political remix, tutoriais em vídeo, entre outros), mas novas ações, procedimentos e atividades (curtir, comentar, redistribuir, compartilhar, taguear, seguir/ ser seguido, remidiar ${ }^{61}$, remixar, curar, colecionar/ descolecionar, colaborar etc.) que supõem o desenvolvimento de outras habilidades. Não se trata de substituição ou de simples convivência de mídias, mas de levar em conta como a coexistência e a convergência das mídias transformam as próprias mídias e seus usos e potencializam novas possibilidades de construção de sentidos. (BRASIL, 2018, não paginado, grifos nossos).

Essas discussões sugeridas na BNCC reforçam, ainda, a urgência em orientar o ensino com base em gêneros no contexto escolar, conforme mostra a proposta pedagógica elaborada por Rose e Martin (2012, p. 63-66), em que os autores apresentam o processo cíclico de aprendizagem desenvolvido e aplicado na Escola de Sydney, ressaltando a importância de aprender a ler e escrever com base em gêneros.

A proposta pedagógica elaborada por Rose e Martin (2012) ressalta as três fases desse processo, as quais são: a Desconstrução, a Construção Conjunta e a Construção Independente do gênero em estudo. Nessa abordagem, prevista inicialmente para o ensino presencial, é possível observarmos que a desconstrução do gênero, ou modelagem, assim 
como as outras fases, poderiam acontecer a qualquer momento, sem necessidade de as etapas serem sequenciais, dependendo das necessidades do público envolvido (MARCHEZAN, 2018, p. 46; REIS, 2017).

Por acreditarmos que os pressupostos teóricos apresentados por Rose e Martin (2012) sejam viáveis para o estudo de gêneros multimodais em aula de LP, buscamos efetivar essa abordagem no design de materiais didáticos digitais ${ }^{2}$ em investigação no nosso grupo de pesquisa NUPEAD (REIS, 2017). Em vista disso, planejamos, criamos e testamos atividades de leitura e escrita por meio do curso LeR Info, inserindo no design do MDD tais pressupostos como uma alternativa para fomentar também o engajamento dos alunos na resolução das atividades.

Com a intenção ainda de concretizar práticas inovadoras que promovam $o$ consumo, a distribuição e a produção de gêneros multimodais em sala de aula, aliando ao uso de tecnologias, ao explorar novos sentidos e semioses encontrados em gêneros e mídias, na próxima seção apresentamos os procedimentos metodológicos adotados para coleta e interpretação dos dados obtidos por meio do MDD aplicado em sala de aula.

\section{Metodologia}

Para planejarmos o MDD do curso LeR Info, realizamos inicialmente uma pesquisa-ação em contexto escolar público estadual, na periferia de Xxxxxxxx, S. A presente pesquisa teve aprovação do Comitê de Ética da Universidade Federal de Santa Maria, sob o número 66229517.1.0000.5346, e por meio de uma pesquisa aplicada e participante, buscamos "possibilitar a participação dos membros da comunidade estudada, ao longo da pesquisa, na análise e interpretação dos dados" (MOTTA-ROTH; HENDGES, 2010, p. 114).

Ao analisarmos os dados em uma abordagem qualitativa, houve interação entre pesquisadora e pesquisados na busca de soluções para problemas encontrados em sala de aula. Para coletarmos dados, primeiramente, aplicamos questionários diagnósticos. Após, planejamos e desenvolvemos o MDD em formato de curso híbrido a partir de três ações: 1) implementar o material que contemple as habilidades de leitura e de escrita, a prática de multiletramentos e o uso de tecnologias; 2) testar o produto em sala de aula; 3) avaliar o MDD proposto.

Para coletarmos dados, dividimos a pesquisa em três fases, envolvendo na primeira fase um total de 31 participantes provenientes da escola pública, incluindo duas turmas distintas. Esses alunos estavam nos anos finais do En- 
sino Fundamental e de Ensino Médio, e por meio da pesquisa buscamos identificar por meio da aplicação de questionários diagnósticos os seus interesses quanto aos temas em discussão em seus contextos sociais, bem como seus interesses quanto ao estudo da língua materna.

Para testarmos o MDD do curso LeR Info, planejamos um estudo de caso e escolhemos a turma de $3^{\circ}$ ano do Ensino Médio por serem alunos pré-vestibulandos e porque fariam a prova do Enem, portanto esse público tinha urgência em desenvolver habilidades de leitura e de escrita de gêneros multimodais. $\mathrm{O}$ presente estudo baseia-se somente nos dados coletados pelos questionários e o curso concluído por esses participantes do $3^{\circ}$ ano do Ensino Médio, os quais nomeamos como participantes \#Pxx, \#Pxy, sucessivamente.

A turma participante era composta por seis alunos com faixa etária entre 17 e 19 anos, residentes nos bairros próximos à escola, sendo que destes três alunos exerciam função remunerada em turno inverso ao das aulas. No início do curso, a turma continha seis alunos regularmente matriculados, porém dois alunos foram transferidos e uma aluna cancelou a matrícula. Por fim, apenas três alunos participaram de todas as etapas do curso, finalizando-o.

Para procedermos à coleta, análise e interpretação de dados, os alunos responderam a questionários impressos e por meio do Google Formulário. Para a criação do curso e design do material, aplicamos as Etapas de Produção de MDD, elaboradas por Reis e Gomes (2014). O material foi proposto no formato de curso híbrido para o ensino de língua portuguesa e explora recursos digitais para potencializar o consumo, a produção e a disseminação de gêneros multimodais tais como o Infográfico, dado a importância que esse gênero circula em diversos contextos sociais, porém ainda é pouco explorado nas práticas escolares, conforme identificamos a partir de pesquisa exploratória realizada em artigos publicados em Linguística Aplicada (MARCHEZAN, 2018) e a partir da análise dos dados obtidos pelo questionário de diagnóstico.

Após, implementamos o MDD na plataforma Google Classroom (GC), iniciamos a sua testagem e procedemos à sistematização e à análise da participação dos alunos na plataforma, no WhatsApp e no software Canva. Na pesquisa de Marchezan (2018), foram levados em consideração comentários dos alunos gravados em áudios durante as aulas, fotografias, feedbacks em intervenções orais e na plataforma e diário reflexivo da pesquisadora. Neste artigo, nos limitamos a apresentar dados coletados pela plataforma GC para análise e descrição das atividades propostas, bem como os obtidos por meio dos questionários. 


\section{Análise das práticas de leitura e escrita por meio do curso LeR Info - Ler e Redigir Infográficos Online}

Para planejarmos o LeR Info aplicamos questionários diagnósticos a fim de identificar interesses e perfil dos alunos. Os dados obtidos nos questionários e os registros em diários de pesquisa pela professora-pesquisadora confirmam que, no contexto escolar, geralmente, os alunos têm contato com os gêneros discursivos por meio de material impresso tais como livro didático, jornais, folhas distribuídas pelos professores, etc., porém, raramente os educadores trabalham com gêneros multimodais em contexto digital, embora a maioria os alunos estejam conectados e possuam amplo acesso às tecnologias nos dias atuais (MARCHEZAN, 2018).

Investigamos quais gêneros multimodais os alunos consomem, produzem e distribuem na internet; diagnosticamos que, segundo os alunos participantes, eles reconhecem diferentes gêneros, tais como: crônica, conto, romance, poesia, charge, HQs, tirinha, entre outros, entretanto não os classificam como gêneros multimodais e não os produzem em/para contexto digital (MARCHEZAN, 2018, p. 115). Tal constatação reforça o que Rojo e Barbosa (2015) afirmam sobre as escolas relegarem a segundo plano o letramento digital, sendo assim, há a necessidade de ampliarmos os estudos sobre o ensino da LP por meio de multiletramentos, levando em conta a linguagem como prática social

A partir dos dados sintetizados, concluímos que: a) devido às recorrentes dificuldades que os alunos de educação básica apresentam ao lerem gêneros multimodais, conforme apontam estudos prévios (DUARTE, 2008, p. 14; BONAMINO; COSCARELLI; FRANCO, 2002, p. 108), elaborar uma proposta do MDD é viável, pois os alunos selecionados dispõem de acesso à internet; b) trabalhar com gêneros multimodais é importante, já que os alunos participantes afirmaram que não reconhecem quais são; c) se os alunos preferem ler a escrever, o infográfico parece ser uma boa alternativa, pois exige que sejam exploradas as habilidades de leitura e de escrita, e a prática de síntese de informações (MARCHEZAN, 2018, p. 75). Além disso, notamos que o infográfico se trata de um gênero multimodal bastante utilizado nas publicações de notícias em geral, o que facilita para coletarmos exemplares tanto no formato impresso quanto digital.

Considerando que os alunos desconhecem a terminologia "produção colaborativa", outro conceito a ser incluído no desenvolvimento do material é esse, pois é preciso apresentar tarefas que promovam esse tipo de produção para que os alunos possam interagir com seus pares 
de modo significativo. Esses resultados nos auxiliaram a elaborar a proposta do curso LeR Info, a qual descrevemos na sequência.

\section{A plataforma, o programa e os objetivos do curso LeR Info}

Conforme o site do Google, a plataforma Google Sala de Aula ou Google Classroom (GC) "é um serviço da Web gratuito para escolas, organizações sem fins lucrativos e para qualquer pessoa com uma conta do Google pessoal" que deseje utilizá-lo com objetivos voltados ao contexto educacional. O GC é mais um aplicativo livre do Google, pelo qual alunos e professores se conectam, utilizando uma conta pessoal ou institucional/educacional de Gmail.

O curso LeR Info foi implementado na plataforma GC e tem como objetivo "Promover o consumo, a produção e a disseminação do gênero multimodal infográfico com vistas a aprendizagem de LP e a prática de multiletramentos por meio de TIC" (MARCHEZAN, 2018, p. 83-84). Esse curso prevê 30 horas-aula, sendo 28 na modalidade híbrida e duas a distância. Todos os materiais foram disponibilizados no GC ou encaminhados via WhatsApp, para que os alunos pudessem acessar o conteúdo em qualquer lugar e horário.
Na plataforma GC, o professor cria uma turma e tem à sua disposição um repositório para materiais diversos, pois pode criar tarefas, enviar avisos e iniciar instantaneamente debates com a turma, verificar quem concluiu ou não um trabalho, dar feedback direto, em tempo real e, ainda, atribuir notas às tarefas. Além disso, o professor poder acompanhar o progresso de seus alunos, avaliá-los, etc., o que permite estarem conectados com um fim pedagógico. Os alunos podem compartilhar recursos uns com os outros e interagir no mural da turma ou por e-mail.

A Figura 1 ilustra a tela inicial do curso LeR Info, que foi nomeado como Turma 311. No Mural estão os conteúdos e as tarefas do curso; em Alunos está a lista de alunos da turma; e em Sobre podemos visualizar os resumos dos trabalhos realizados, acessar a pasta da turma no Drive e a agenda da plataforma GC. Na tela inicial, é possível localizar informações sobre as professoras desenvolvedoras na pesquisa e no curso. 
Figura 1 - Tela inicial do curso no GC

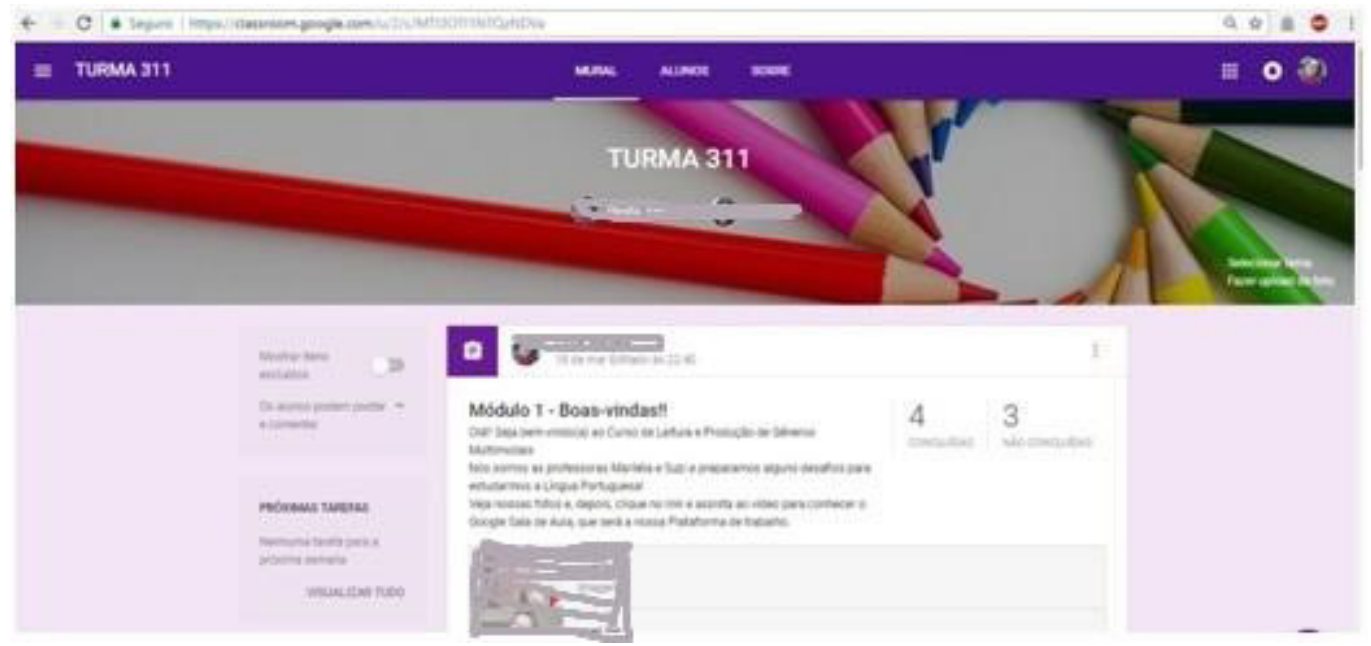

Fonte: Banco de dados do Núcleo de Pesquisa, Ensino e Aprendizagem de Línguas a Distância (NUPEAD).

A plataforma GC possui diversos recursos, dos quais se destacam: a permissão para anexar links, vídeos do YouTube e arquivos do Google Drive; e fazer upload de arquivos do computador. Para ilustrar como foram feitas algumas implementações para acesso dos alunos à plataforma criamos, no Módulo 1, um vídeo para dar as boas-vindas. Nesse vídeo, as professoras são apresentadas à turma. Embora o GC possibilite a colaboração e a interação entre os pares, a plataforma é limitada para elaborar um design gráfico mais rico do material/ conteúdo proposto, de modo que fique atraente, dinâmico, hipertextual e interativo.

O programa do curso foi dividido em sete Módulos, em cada Módulo, buscamos disponibilizar e explorar recursos diferentes. No Módulo 1, buscamos dar noções gerais sobre o uso da ferramenta GC, a fim de familiarizar o aluno com a plataforma e promover ainda a fluência e o letramento digital dos participantes. No Módulo 2, os alunos exploram gêneros já conhecidos, conceituam gêneros discursivos e multimodais, e iniciam o estudo sobre o gênero infográfico. No Módulo 3, ocorre a análise e a desconstrução do gênero infográfico. O Módulo 4 promove pesquisa, consumo e desconstrução de outros exemplares de infográficos; e incentiva o uso do software Canva para testagem de produção de textos multimodais.

No Módulo 5, há a preparação para a atividade de produção de infográfico (pesquisa, síntese das informações e escrita colaborativa do resumo/relatório 
da pesquisa) para a produção conjunta de um infográfico. No Módulo 6, dá-se a produção colaborativa do gênero infográfico no Canva (produção, edição, revisão, feedback da $1^{\text {a }}$ versão, reedição e socialização dos infográficos produzidos com colegas e professora). E, finalmente, no Módulo 7, realiza-se a produção independente do gênero infográfico no software Canva (produção, edição, revisão, feedback da $1^{\text {a }}$ versão, reedição e socialização dos infográficos com os colegas e professora) e incentiva a disseminação da produção em diferentes mídias ou redes sociais.

A Avaliação da aprendizagem dá-se em um processo contínuo ao longo do curso. Em cada Módulo, avalia-se o engajamento do aluno, a realização das tarefas/desafios propostos por meio de postagens no GC e no Google Drive, as intervenções orais do aluno, bem como a produção e a disseminação do gênero em estudo, conforme as etapas da pedagogia de gêneros (MARCHEZAN, 2018, p. 84-85). Ao término do curso, temos como objetivo que o aluno seja capaz de consumir, produzir e disseminar o gênero multimodal infográfico.

Essa proposta é a primeira versão aplicada e avaliada em contexto de sala de aula, do contexto escolar público. Neste artigo, descrevemos, ainda, exemplos de atividades de leitura e escrita desenhadas na plataforma online, para uso em aula, na modalidade híbrida.

\section{Exemplos de atividades de leitura e escrita do curso LeR Info}

Neste artigo nos limitamos a apresentar alguns exemplos de tarefas de leitura e escrita ofertadas na plataforma, tendo por base a concepção de linguagem como prática social, a fim de ilustrar a aplicação prática da pedagogia de gêneros implementada no design do curso. Mais detalhes sobre o curso podem ser encontrados diretamente na plataforma Google Classroom ${ }^{3}$ ou na dissertação de Marchezan (2018).

No Módulo 2, por exemplo, propomos atividades em que os alunos tiveram um primeiro contato com os gêneros multimodais, conforme mostra a Figura 2. A postagem elaborada pela professora convidava o aluno a explorar esses gêneros, ao navegar em uma proposta de conteúdo disponibilizado no formato de uma apresentação em PowerPoint. Com a limitação da plataforma para desenhar e criar o conteúdo diretamente na postagem, a alternativa encontrada para apresentar o conteúdo deu-se no formato de apresentação PowerPoint. 
Figura 2 - Módulo 2

$\equiv$ TURMA 311

目 Módulo 2 - Descobrindo os GÊNEROS

MULTIMODAIS

Profa. 18 de mar. de 2018 Editado às 4 de out. de 2018

100 pontos

Data de entrega: 4 de out. de 2018

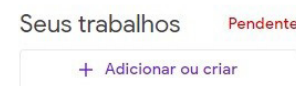

Neste curso, iremos trabalhar com GÊNEROS MULTIMODAIS!

Então, primeiro, vamos entender O QUE SÃO ESSES GÊNEROS?

Para isso, vamos a atividade 1 ?

Veja 0 arquivo abaixo!

$\begin{array}{ll}1 & \text { ATIVIDADE 1.pptx } \\ y & \text { Apresentações Google }\end{array}$

Comentários particulares

Marcar como concluida

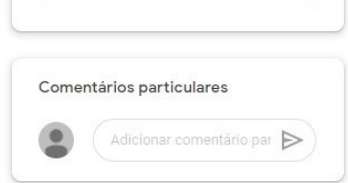

Fonte: banco de dados do NUPEAD.

Inicialmente, propusemos atividades em que os conhecimentos prévios dos estudantes sobre gênero discursivo são ativados por meio de uma atividade presencial, mediada pela professora, em sala de aula, de modo expositivo dialogado. Nesse momento, os alunos puderam acompanhar o conteúdo em uma apresentação, disponível no GC, com imagens de textos multimodais e questionamentos, a fim de conduzi-los a identificar os textos propostos, seus objetivos e função social. Essa atividade foi realizada oralmente em sala de aula. Após o reconhecimento dos gêneros propostos e a discussão dialogada com os alunos, consideramos importante conceituar o que são gêneros multimodais, segundo Cope e Kalantzis (2015).
A sequência dos módulos orientou-se pelos pressupostos da pedagogia de gêneros e suas etapas cíclicas (ROSE; MARTIN, 2012), explorando uma diversidade de atividades. Com a intenção de testar a modalidade híbrida e a metodologia ativa sala de aula invertida, durante o curso, antes da aula presencial, pelo grupo da turma no WhatsApp, os alunos foram desafiados a pensar sobre 0 gênero multimodal infográfico, conforme demonstra a Figura 3. 
Figura 3 - Desafio enviado pelo WhatsApp e Formulário disponibilizado no Drive como tarefa a distância no Módulo 2

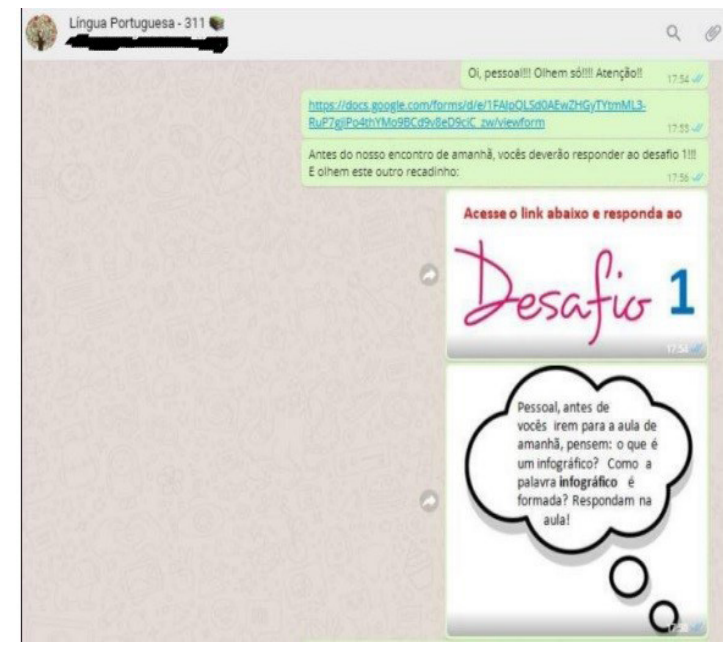

\section{DESAFIO 1}

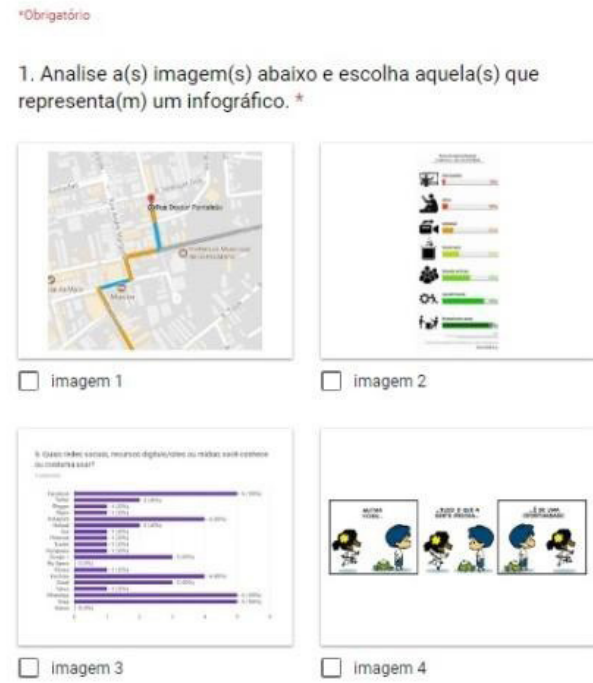

2. Por que você escolheu essa imagem para marcar? E por que não escolheu as outras? Justifique sua resposta. *

Fonte: banco de dados do NUPEAD.

Para a realização dessa atividade, foi postado o link do Formulário do Google no grupo do WhatsApp da turma. Essa atividade de leitura teve a intenção de preparar os alunos para o Módulo 3, ativando conhecimentos prévios e aguçando sua curiosidade sobre o gênero infográfico. No Módulo 3, procedemos à etapa de Desconstrução do gênero multimodal infográfico com o estudo de alguns exemplares desse gênero. Essa atividade foi realizada em sala de aula presencial de modo colaborativo, contando com a mediação da professora para o estudo do gênero infográfico. A partir da análise conjunta de exemplares (impressos e digitais) os alunos podiam identificar como a linguagem se realiza no texto, bem como sua função social e os elementos de sua composição, explorando-os e questionando-os junto à professora.

Nesse módulo ainda, os alunos trabalharam em duplas na busca de resolução de desafios com perguntas relacionadas ao gênero analisado. A intenção era preparar o aluno para a produção de um infográfico na sequência. Sendo assim, antes da aula presencial, os alunos iniciaram as atividades do módulo 4 estudando a distância, buscando refletir sobre o processo de produção de um infográfico, bem como conhecendo o software Canva por meio de um tutorial do YouTube. 
Após as experiências com consumo de gêneros, era importante oportunizar aos alunos a produção escrita. Por isso, no módulo 5, os alunos receberam orientações para iniciarem a produção de um infográfico. Para esse processo, primeiramente, os alunos realizaram intenso trabalho de pesquisa sobre o tema (escolhido pelos estudantes, juntamente com a professora, sobre um assunto relacionado ao contexto social da turma) que seria abordado nas produções. Na sequência, procuramos promover a Construção Conjunta do gênero em estudo, e os alunos, em grupo, produziram exemplares de infográficos.

Para essa atividade, primeiramente os alunos pesquisaram informações em diversos sites e realizaram entrevistas com profissionais sobre o tema escolhido. Após resumirem as informações, de forma colaborativa e compartilhada com o uso do Google Drive, iniciaram o processo de produção do gênero infográfico no software Canva. A Figura 4, à esquerda, representa a versão final dessa produção. Além da experiência de produção colaborativa, na pedagogia de gêneros é incentivada a produção individual. Em vista disso, no Módulo 7, os estudantes foram desafiados a produzir individualmente um exemplar do gênero em estudo (ver Figura 4, à direita). Para essa produção, cada aluno escolheu uma temática, realizou pesquisas e criou um infográfico de forma independente no Canva. Após a revisão da professora, os alunos concluíram a versão final.

Figura 4 - À esquerda, infográfico produzido de forma colaborativa pelos alunos; à direita, infográfico produzido de forma independente por um aluno

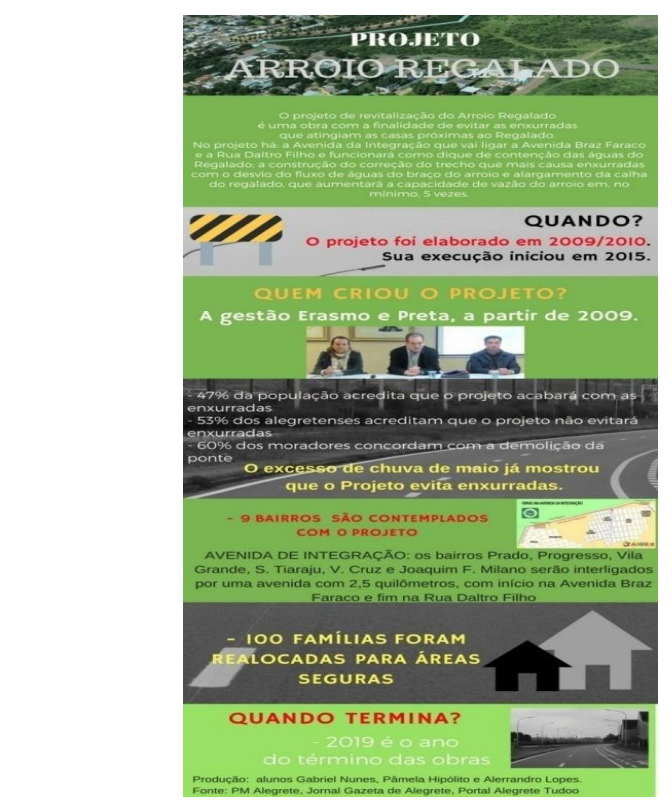

Fonte: banco de dados do NUPEAD.

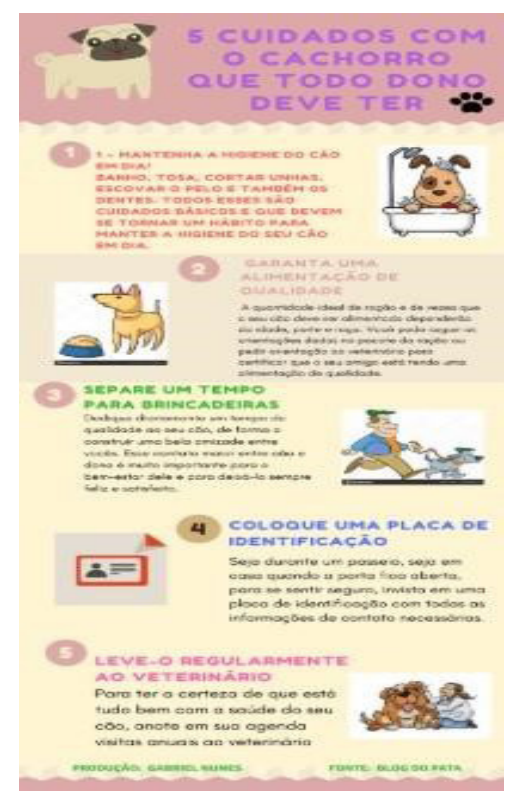


A partir das atividades propostas no curso consideramos que a interação com esses processos de análise e de produção fizeram com que o aluno explorasse de modo mais sistemático o gênero em estudo (léxico, elementos linguísticos, propósito comunicativo, processos verbais, etc.). Ao planejarmos e aplicarmos as atividades no formato de desafios, levamos em consideração que o letramento da imagem e do signo visual deve ser incorporado à escola (DIONÍSIO, 2008), por isso buscamos meios, com alunos de Ensino Médio, para preencher uma lacuna quanto ao estudo de textos multimodais e propusemos um curso que explorasse diversos recursos semióticos (leitura de imagens, gráficos, cores, formas, entre outros).

Ao concluírem o curso, os alunos compartilharam os infográficos produzidos com os colegas e a professora. Para essa produção escrita multimodal, os alunos utilizaram os recursos do Canva, do Google Drive e do WhatsApp. Além disso, buscamos incentivar que a produção feita no contexto escolar tivesse a sua disseminação além dos muros da escola, por isso como fator motivador, previmos também que as produções seriam compartilhadas na mídia local (jornais da cidade). Dessa forma, os alunos levaram em conta que deveriam criar textos bem elaborados os quais seriam apresentados aos leitores dos jornais. Por fim, contatamos um jornal de grande circulação da cidade, o qual aceitou publicar a versão final dos infográficos produzidos de forma colaborativa.

Dados coletados por meio de questionários avaliativos (QA), durante e ao final da aplicação do curso, nos apontam resultados positivos quanto ao estudo da LP com o auxílio das tecnologias, como podemos ver no relato dos alunos que avaliaram o curso. Para essa avaliação, tomamos como referência respostas dadas pelos participantes nos QA. Segundo o \#P29, "o projeto foi bem desafiador, mas as aulas se tornaram melhores do que ficar trabalhando só com textos". Para o \#P30, "a aula foi mais interessante depois da chegada do projeto"; e o \#P31 afirmou que para ele "foi válido, aprendi bastante e também achei interessante".

Observamos que o \#P29 avalia o MDD como desafiador e usa o conector mas para apresentar aspecto positivo. Com isso, entendemos que o aluno encontrou certa dificuldade na realização do curso, porém os aspectos positivos do projeto sobressaíram--se, conforme a avaliação dele.

Além desses dados, inferimos ao final da experiência que a aplicação do MDD contribuiu para promover as habilidades de leitura e de escrita, pois os alunos exploraram sites, resumiram informações, selecionaram imagens e produziram infográficos. Por meio das atividades e durante as produções dos alunos, é notável o consumo, a produção e a disseminação do gênero em estudo. Como foi utilizado 
o software Canva na versão free, há poucos recursos gratuitos disponíveis, ainda assim os alunos produziram infográficos conforme as características composicionais e as escolhas lexicais próprias do gênero. Os procedimentos propostos pela pedagogia de gêneros e de multiletramentos cumprem seus papéis à medida que os alunos conseguem compreender a estrutura composicional do gênero multimodal infográfico e o reproduzem.

Com relação à aprendizagem da língua portuguesa, embora não esteja explicitado nos módulos do Curso, além das aprendizagens relacionadas à leitura e à escrita de textos multimodais, foi necessário, em vários momentos durante as aulas, explicitar os aspectos léxico-gramaticais que envolveram o emprego correto da acentuação e da pontuação, concordância verbo-nominal, elaboração de resumos, análise e seleção de imagens adequadas a um contexto específico.

\section{Considerações finais}

Sabemos que a prática de multiletramentos contribui para que a linguagem se efetive em práticas sociais, não só no consumo, mas também na produção e na disseminação de textos multimodais. Ao desenvolvermos MDD para a aprendizagem de LP na perspectiva de gêneros e multiletramentos, planejamos um curso híbrido que possibilitasse aos alunos, sujeitos sociais, utilizarem as tecnolo- gias para realizarem suas atividades de forma colaborativa.

Para desenvolvermos o design do curso online, levamos em consideração a intenção comunicativa dos textos por meio de recursos semióticos (KRESS; VAN LEEUWEN, 2001). Constatamos que um dos gêneros pouco estudados em sala de aula é o infográfico, por isso esta pesquisa voltou-se para ele, pois é um gênero composto por diversas semioses e pode atrair a atenção dos alunos, além de ser de fácil produção com o uso de softwares livres.

Este estudo aponta resultados positivos quanto ao ensino da LP por meio de gêneros multimodais e do uso das TIC, tendo em vista que os participantes informaram que as aulas de LP se tornaram melhores e mais interessantes com a aplicação do curso, tornando-os mais preparados para ler e analisar gêneros multimodais, em especial o infográfico, veiculado em diferentes contextos sociais. Diante da avaliação realizada pelos alunos, entendemos que a experiência foi bem-sucedida e inovadora, o que nos motiva a dar continuidade à pesquisa $\mathrm{e}$ propor, futuramente, um novo design do curso para próximas aplicações.

Verificamos, ainda, que o Ciclo de Aprendizagem na perspectiva da $\mathrm{Pe}$ dagogia de Gêneros, proposto por Rose e Martin (2012), é uma possibilidade viável para orientar o design de $\mathrm{MDD}$, com vistas a promover a aprendizagem da língua e, também, por potencializar 
a prática de multiletramentos, por intermédio de atividades tais como a leitura, a produção e a distribuição do gênero em estudo. $\mathrm{O}$ trabalho com infográficos, mediante atividades que partem da desconstrução do gênero, permitiu a compreensão das propriedades comunicativas e das características composicionais próprias desse gênero, bem como a produção colaborativa e individual dos alunos. Os aplicativos WhatsApp, Google Docs, Google Formulário e Canva também foram essenciais para a produção e a distribuição do gênero, bem como as práticas de multiletramentos e, especialmente, de letramento digital.

Aplicar MDD em contexto escolar público é desafiador devido à visão tradicional que muitos ainda possuem. Quando mencionamos isso, referimo-nos à comunidade escolar: pais, equipe gestora, professores, alunos, pois, para a maioria desses agentes sociais, ensinar e aprender produção textual requer práticas mais tradicionais de escrita, manualmente em cadernos, livros didáticos, avaliando a aprendizagem por meio de provas e testes. Além disso, há outros entraves, como a dificuldade de navegação na web na escola, a ausência ou o reduzido número de computadores e o uso restrito de tecnologias móveis em sala de aula. Também é importante enfatizar que muitos estudantes não têm acesso a informações por meio de jornais, revistas ou, inclusive, internet, haja vis- ta faltarem condições econômicas para subsidiarem tais recursos midiáticos, e transformar essa realidade é pertinente e deve fazer parte dos anseios dos educadores conscientes de seus papéis sociais em uma escola libertadora.

Desejamos que os resultados apresentados neste estudo contribuam para a práxis dos educadores, em especial de LP, no sentido de serem "professores facilitadores da autonomia" (FREIRE, 1996), colaborando com a formação de alunos críticos e capazes de reconhecer a importância da linguagem em diferentes práticas sociais e de transformar suas realidades, se assim desejarem. Nesse sentido, é importante ampliarmos as pesquisas quanto à produção de MDD e sua aplicação em contexto escolar, haja vista que este foi um estudo bem específico, com um público limitado. Em vista disso, sugerimos que a proposta aqui apresentada seja reaplicada em outros contextos escolares para testar sua eficácia.

\section{LeR Info: a proposal of digital didactic material for teaching reading and writing infographics in the Google Classroom}

\section{Abstract}

In the field of Applied Linguistics researches report analyse of discoursive and multimodal genres and bring suggestions of didactic sequences to 
use in the class, but rarely researches report the description of digital materials to be used in portuguese classes in a blended modality, highlighting the language as a social practice. Based on these assumptions, we developed a digital teaching material to promote teaching reading and writing by using Google Classroom in a multiliteracy perspective and critical genre-based approach. To evaluate this material, we realized an action research in a public school in whose experience the participants consumed, produced and disseminated the multimodal infographic genre. Results from this experience are positive in relation to language learning, because it engaged and motivated students as well as it demonstrates the student's learning in relation to the genre itself, since their involvement in different social practices by the use of digital technologies.

Keywords: Language as a social practice. Digital teaching material. Multimodal infographic genre. Google Classroom. Reading and writing.

\section{Notas}

1 Este artigo toma por base dados de dissertação de mestrado de Marchezan (2018), do Programa de Pós-Graduação de Tecnologias Educacionais em Rede, defendida na Universidade Federal de Santa Maria, em 14 de agosto de 2018. O levantamento bibliográfico foi realizado durante o período de desenvolvimento de pesquisa de mestrado, a qual foi realizada pela primeira autora.

2 Em comunicação oral em sessão de orientação em 2017. Também se sugere verificar produções do grupo de pesquisa em: http://www.ufsm.br/ grupos/NUPEAD.

3 Disponível em: https://support.google.com/edu/ classroom/answer/6020279?hl=pt-BR. Para acessar como visitante, usar o e-mail labeon@ ufsm.br, senha: tester2018. Em caso de dificuldades, entrar em contato com labeon@ufsm.br

\section{Referências}

MARCHEZAN, M. Desenvolvimento de material didático digital para o ensino de língua portuguesa na perspectiva de gênero e multiletramentos. 2018. 155 f. Dissertação (Mestrado em Tecnologias Educacionais em Rede) - Programa de Pós-Graduação em Tecnologias Educacionais em Rede, Universidade Federal de Santa Maria, Santa Maria, 2018.

REIS, S. C. Ensino de produção oral em língua inglesa por meio de podcast: relatando uma experiência com alunos do ensino fundamental. Revista Veredas, v. 21, n. 1, 2017.

REIS, S. C. Do Discurso à prática: textualização de pesquisas sobre ensino de inglês mediado por computador. 2010. $242 \mathrm{f}$. Tese (Doutorado em Estudos Linguísticos) - Programa de Pós-Graduação em Letras, Universidade Federal de Santa Maria, Santa Maria, 2010.

REIS, S. C.; GOMES, A. F. Podcasts para o ensino de Língua Inglesa: análise e prática de Letramento Digital. Calidoscópio (Online), v. 12, p. 367-379, 2014. Disponível em: http:// revistas.unisinos.br/index.php/calidoscopio/ article/view/cld.2014.123.11. Acesso em: 15. jul. 2017.

BITENCOURT. D de C. Proposta de gestão pedagógica para o ensino de língua portuguesa por meio de dispositivos móveis. 2019. 176 f. Dissertação (Mestrado em Tecnologias Educacionais em Rede) - Programa de Pós-graduação Mestrado Profissional em Tecnologias Educacionais em Rede, Universidade Federal de Santa Maria, Santa Maria, 2019.

BONAMINO, A.; COSCARELLI, C.; FRANCO, C. Avaliação e letramento: concepções de aluno letrado subjacentes ao SAEB e ao PISA. Educação e Sociedade, Campinas, v. 23, n. 81, p. 91-113. 2002. Disponível em: http://www.scielo.br/pdf/es/v23n81/13933. pdf. Acesso em: 10 set. 2018. 
BRASIL. Base Nacional Curricular Comum. Conselho Nacional de Educação, 2018. Disponível em: http://basenacionalcomum.mec. gov.br/abase/\#medio/a-area-de-linguagens-e-suas-tecnologias. Acesso em: 20 jun. 2019.

CATTO, N.; HENDGES, G. R. Análise de gêneros multimodais com foco em tiras em quadrinho. SIGNUM: Estudos da Linguagem, Londrina, v. 2, n. 13, p. 193-217, 2010. Disponível em: http://www.uel.br/revistas/uel/ index.php/signum/article/view/6562/6975. Acesso em: 18 jul. 2017.

CECCHIN, A. de S. Práticas de multiletramentos no contexto escolar: investigação de uma abordagem para o ensino de produção de narrativas digitais. 2015. $168 \mathrm{f}$. Dissertação (Mestrado em Tecnologias Educacionais em Rede) - Programa de Pós-graduação em Tecnologias educacionais em Rede, Universidade Federal de Santa Maria, Santa Maria, RS, 2015.

COPE, B.; KALANTZIS, M. Language Education and Multiliteracies. In: MAY, S.; HORNBERGER, N. H. (org.). Encyclopedia of Language and Education. 2. ed. NY, USA: Springer Science Business Media LLC, 2008. v. 1. p. 195-211.

COPE, B.; KALANTZIS, M. The things you do to know: an introduction to the pedagogy of multiliteracies. In: COPE, B.; KALANTZIS, M. (org.). A pedagogy of multiliteracies. Learning by design. NY, USA: Palgrave Macmillan, 2015. p. 1-36.

COSCARELLI, C. V. Tecnologias para aprender. São Paulo: Parábola Editorial, 2016.

DIONÍSIO, A. Gêneros multimodais e multiletramento. In: KARWOSKI, A. M.; GAYDECZKA, B.; BRITO, K. S. (org.). Gêneros textuais: reflexões e ensino. 3. ed. rev. Rio de Janeiro: Nova Fronteira, 2008. p. 131-144.

DUARTE, V. M. Textos multimodais e letramento: habilidades na leitura de gráficos da Folha de São Paulo por um grupo de alunos de Ensino Médio. 2008. 219 f. Dissertação (Mestrado em Tecnologias Educacionais em Rede) - Programa de Pós-graduação em Letras, Universidade Federal de Belo Horizonte, Belo Horizonte, MG, 2008.

FREIRE, P. Pedagogia da autonomia: saberes necessários à prática educativa. 25. ed. São Paulo: Paz e Terra, 1996. Disponível em: http://forumeja.org.br/files/Autonomia.pdf. Acesso em: 21 out. 2017.

FUZER, C. Ateliê de textos: (Re) invenção e (re) escrita de histórias no ensino básico. Revista da Anpoll, Florianópolis, n. 37, p. 56-79, jul./dez. 2014. Disponível em: https:// revistadaanpoll.emnuvens.com.br/revista/ article/view/772. Acesso em: 30 ago. 2018.

FUZER, C. Bilhete orientador como instrumento de interação no processo ensino aprendizagem de produção textual. Letras, Santa Maria, v. 22, n. 44, p. 213-245, jan./ jun. 2012. Disponível em: . Acesso em: 28 out. 2018.

HYLAND, K. Genre pedagogy: language, literacy and L2 writing instruction. Journal of Second Language Writing, v. 16, p. 148-164, 2007. Disponível em: https://www.researchgate.net/publication/228645075_Genre_ pedagogy_Language_literacy_and_L2_writing_instruction. Acesso em: 15 out. 2018.

JESUS, D. M.; CARBONIERI, D. Práticas de multiletramentos e letramento crítico: outros sentidos para a sala de aula de línguas. Campinas, SP: Pontes Editores, 2016. (Coleção Novas Perspectivas em Linguística Aplicada, v. 47).

KRESS, G.; VAN LEEUWEN, T. Multimodal discourse: the modes a media of contemporary communication. Londres: Arnold; New York: Oxford University. on: Arnold, 2001.

MOTTA-ROTH, D. A construção social do gênero resenha acadêmica. In: MEURER, J. L.; MOTTA-ROTH, D. (org.). Gêneros textuais e práticas discursivas: subsídios para o ensino da linguagem. Bauru, SP: EDUSC, 2002. p. 78-79. 
MOTTA-ROTH, D. O ensino de produção textual com base em atividades sociais e gêneros textuais. Revista Linguagem em (Dis)curso, v. 6, n. 3, p. 495-517, set./dez. 2006. Disponível em: http://www.portaldeperiodicos.unisul. br/index.php/Linguagem_Discurso/article/ viewFile/347/368. Acesso em: 10 set. 2017.

MOTTA-ROTH, D.; HENDGES, G. R. Produção textual na universidade. São Paulo: Parábola Editorial, 2010.

RIBEIRO, A. E. Multimodalidade e produção de textos: questões para o letramento na atualidade. Signo, v. 38, n. 64, p. 21-34, jan./jun. 2013. Disponível em: https://online.unisc.br/ seer/index.php/signo/article/view/3714/2554. Acesso em: 18 fev. 2017.

RIBEIRO, A. E. Textos multimodais leitura e produção. São Paulo: Parábola Editorial, 2016.

ROJO, R. H. R. Pedagogia dos multiletramentos. In: ROJO, R.; MOURA, E. (org.). Multiletramentos na escola. São Paulo: Parábola Editorial, 2012. p. 11-31.

ROJO, R. H. R.; BARBOSA, J. (org.). Hipermodernidade, multiletramentos e gêneros discursivos. São Paulo: Parábola Editorial, 2015.

ROJO, R.; MOURA, E. (org.). Multiletramentos na escola. São Paulo: Parábola Editorial, 2012.

SOJO, C. A. La infográfia peridística. Caracas, Venezuela: Fondo Editorial de Humanidades e Educación; Universidade Central de Venezuela, 2000.

SOUZA, J. A. C. O infográfico e a divulgação científica midiática (DCM): (entre) texto e discurso. 306 f. Tese (Doutorado em Linguística Aplicada) - Programa de Pós-graduação em Linguística Aplicada, Universidade do Vale do Rio dos Sinos, São Leopoldo, 2012. Disponível em: http://www.repositorio.jesuita.org.br/handle/UNISINOS/4460. Acesso em: 20 jun. 2018.
ROSE, D.; MARTIN, J. R. Learning to write, Reading to learn. Equinox: UK, 2012.

WALSH, M. Multimodal literacy: What does it mean for classroom practice? Australian Journal of Language and Literacy, v. 33, n. 3, p. 211-239, 2010. Disponível em: https:// www.alea.edu.au/documents/item/63. Acesso em: 12 mar. 2018. 